\title{
INTERNATIONAL CONFERENCE CITIES IN MOVEMENT: MIGRANTS AND URBAN GOVERNANCE
}

\author{
JoÃo Diogo Mateus ${ }^{1}$
}

On November 11-12, 2002, the Chancellery of the University of Lisbon hosted the International Conference Cities in Movement: Migrants and Urban Governance, organised by the Project Reinventing Portuguese Metropolises - Migrants and Urban Governance, which is coordinated by Prof. Maria Lucinda Fonseca and hosted by the Centre of Geographic Studies (CEG).

The conference comprised four thematic panels, in which a number of invited speakers participated alongside the members of the research team of the aforementioned project. These invited speakers included some of the most reputed specialists from Europe and North America in the field of international migration.

The first panel, entitled Knitting the City: Planning for Ethnic Cities, was chaired by Jorge Malheiros (CEG, University of Lisbon) and included three addresses in which the speakers discussed the recent developments affecting ethnic cities, as well as the way in which the existing urban policies have sought to address the challenges that arise from hosting immigrant populations. Marco Martiniello, of the University of Liège, analysed multicultural policy in the city of Brussels and the political participation in the October 2000 local elections, in his address "Brussels: a multicultural policy?". After arguing that Brussels is one of the most nationally and ethnically diverse European cities - roughly one half of its population descends from immigrants and foreign citizens -, Martiniello emphasised the changes in the patterns of electoral participation of the Belgian citizens of Turkish and (especially) Moroccan descent, setting the success of these politicians against its broader context and calling the attention onto the feeble participation of the citizens of other EU countries.

Audrey Singer (The Brookings Institution, Washington, DC) presented a paper entitled "Contemporary immigrant settlement and the emergence of new gateways in metropolitan USA", in which she sought to present a typology of the immigrant gateway cities and of the urban policies that are required in order to deal with the increasing migratory inflows to new receiving areas. Singer analysed the growth of these new immigration cities, particularly Atlanta, Dallas and Washington, DC - cities that are characterised by an increase in the immigrant population over the past twenty years, particularly in the

1 João Diogo Mateus is a Research Fellow working with the Project Reinventing Portuguese Metropolises - Migrants and Urban Governance (FCT - POCTI 38599/GEO/2001), coordinated by Prof. Maria Lucinda Fonseca. E-mail address: diogomateus@fl.ul.pt. 
1990s. Only recently has policy in these new gateway cities undergone major changes in response to the challenges to the public policies and institutions brought forth by the increase in immigration. The speaker stressed the need for the various institutions to be able to adapt quickly to an evolving environment, particularly in what regards integration policies for the recently arrived. The language issue, both in public schools and in public services in general, is one of the earliest and major challenges to be faced by immigrant gateway cities.

In her address "New directions of urban policies against social and economic exclusion", Maria Lucinda Fonseca (CEG - University of Lisbon) analysed the new urban policies against social exclusion in the context of the process of urban redevelopment taking place in the city of Lisbon. The recent changes in the urban social structure, the income inequality between the various social groups and the new forms of poverty and social exclusion that are associated with unemployment, demographic ageing and ethnic diversity have all resulted in a fragmented city that reflects the major changes going on in the city. The management of the resulting conflicts necessarily involves designing new policy packages that are able of maintaining the fine balance between economic competitiveness and social cohesion, at both the urban and metropolitan levels. After highlighting the most relevant recent changes in the orientation of the public policies to tackle social and ethnic exclusion, Lucinda Fonseca identified three main trends in the field of urban policy: 1) urban policies aimed at strengthening local institutions and involving the population at the local level, thereby allowing for the creation of socially sustainable environments; 2) urban policies that have a strong spatial component and underlying philosophy; and 3) the replacement of the traditional sectoral policy approach with integrated multi-sectoral strategies. This speaker concluded with some thoughts on the new challenges to urban governance, based on the present experience in the Lisbon Metropolitan Area.

The second panel, "Living in the City: The New Socio-Cultural Dynamics", was chaired by Diogo de Abreu (CEG - University of Lisbon) and focused on the issues concerning the daily lives of immigrants and immigrant groups in ethnically diverse cities. In his address "The individual and the group: cultural and social capital - enabling change in the ethnic city", Paul White (University of Sheffield, UK) analysed the relationship between the goals pursued by the individual and those pursued by the groups of which he/she is a member. The city was presented as a fluid, hybrid space, in which the individuals (re)create their identities and ways of life and in which permanent tensions occur between the various personal and group goals pursued by the individuals (ethnic identity being but one of the spheres determining those goals). Paul White argued that individuals use their cultural capital in order to act within the ambit of their various social spheres and that coexistence within those spheres in turn reinforces their cultural capital. At yet another level, cultural capital is used by networks and groups to strengthen their organisational and negotiating capacity. London and Paris provide interesting examples from ethnically diverse cities of how individuals accumulate and use cultural capital.

Fabio Quassoli (Department of Sociology - University of Milan) reflected upon immigrant marginalisation and the fear of crime in his address "Making the neighbourhood safer: social alarm, police practises and immigrant exclusion”. The main argument in this address was the reliance upon the criminal/illegal alien categories by the Italian police, which often confuses the illegal status of the immigrant and the assumption that he/she is involved in criminal activities. This sort of conceptual categories is used both for administrative purposes and in preventing crime and exercising repression, even 
when dealing with deviant behaviour that is not formally criminal. The intentional reliance upon these misleading categories causes social alarm, raises serious questions regarding safety and social control in the city and some even more serious questions with regard to how the Italian society deals with immigration. Quassoli actually argues that the police plays an active part in criminalizing immigrants and maintains that the argument that deportation is the only way to deal with immigrant criminals is a dangerous and potentially disastrous one. This speaker also considered that this criminalizing of certain immigrant groups in Italy - particularly the Albanians, Moroccans, Romanians and former-Yugoslavs - falls nothing short of turning them into scapegoats for the social problems of the Northern and Central Italian cities.

Alina Esteves (CEG - University of Lisbon) gave out an address entitled "Hosting policies in Lisbon and Washington, DC: the role of local actors in the integration of immigrants", in which she claimed that, in spite of the numerous differences between these two cities and their respective metropolitan areas, they have one thing in common: the fact that both recently experienced a substantial growth in their resident (and working) immigrant populations, particularly from the 1980s onwards. Despite the differences between the rates of increase in the two cities, this common characteristic enables us to adequately characterise both of them as new immigration cities. Throughout her address, Alina Esteves pinpointed the various local actors that, in Lisbon and Washington, DC, play a part in the hosting and integration of immigrants: from the local authorities to immigrants' associations, to other NGOs that indirectly advance immigrants' rights (residents' associations, task forces), to private social solidarity institutions that provide lowcost health care to citizens without access to health insurance schemes (US) or to families in need (Portugal). In the case of the US, the importance of the private foundations and public charities in funding project development by immigrants' associations and other NGOs was also highlighted. The speaker then proceeded to identify the main differences between the two metropolitan areas with regard to the hosting of immigrants: 1) the maturity of the migratory phenomenon; 2) the participation of the citizens in the decision-making process; 3) welfare schemes; 4) political and administrative structures; and 5 ) the role and significance of private funding. Finally, Alina Esteves mentioned a number of best practises in the field of immigrant hosting and integration in the two cities.

In his paper "Lost in Lisbon: homeless immigrants surviving on the street", João Diogo Mateus (CEG - University of Lisbon) reflected upon the nature of the causes that lead hundreds of Eastern European immigrants to spend the night on the streets or in shelters for the homeless and to rely on social protection instruments that were primarily designed for the homeless population - despite the fact that some live in hostels or share apartments with other individuals in a similar situation. Over the past three years, experts and volunteers working with the homeless have increasingly reported a new type of homelessness that is particularly worrisome due to the lack of adequate responses: undocumented Eastern European immigrants barely surviving on the streets of Lisbon, unable to pay for an apartment, exploited by unscrupulous employers and facing serious debt problems with criminal organisations. By interviewing people working in the field, Diogo Mateus sought to identify the institutional responses to the specific vulnerabilities that turn undocumented Eastern European immigrants into the fastest-growing homeless sub-group in Europe, estimated by some experts to account for 30-40 per cent of the homeless population in the city of Lisbon. Towards the end of his address, this speaker analysed the impact of the restrictive nature of the Portuguese law (with regard to the entry and permanence of aliens in the Portuguese territory) upon the social exclusion trajectories of undocumented immigrants, particularly those that have recently arrived 
and are not yet able to rely on co-ethnic social assistance networks.

The third panel, which was chaired by Alina Esteves and entitled Working in the City: Constructing Multi-Ethnic Economies, inaugurated the second day of the conference. Lorenzo López-Trigal (University of Léon) reaffirmed the significance of immigration in the major Spanish cities in his address "Recent immigration trends in Spain and their repercussions in urban areas". The speaker began by providing an overview of the Southern European migration system with a special focus on the Spanish case. LópezTrigal then analysed the demographic, social, economic and cultural features of the recently-arrived immigrant population in Spain, while taking the situation in the sending countries into account. Case-studies like Madrid or Barcelona were used in order to illustrate the integration processes of these immigrants in the Spanish cities.

Diogo de Abreu (CEG - University of Lisbon) discussed some of the problematic aspects involved in designing a prospective model aimed at forecasting the future demand for immigrant labour in the Portuguese labour market. The goal of his address, "Immigration and labour market changes in Portugal: towards a forecasting model", was two-fold: to review the various models that seek to adequately portray the Portuguese labour market; and to discuss ways in which these models might best be used to predict the future patterns of immigration to Portugal.

Maria José Caldeira (Department of Geography-Minho University) brought us an analysis of the recent Portuguese emigration to Geneva, in "The recent Portuguese emigration: a forgotten reality? A portrait from the resident community in Geneva". Switzerland is one of the main receiving countries for Portuguese emigration and Geneva stands out as one of the top destinations. The main goal of this paper was to analyse the differences and similarities between the current emigration wave and that of the 1960s and 1970s, and to understand the explanatory factors behind the present wave. A particularly interesting aspect was the analysis of the professional incorporation of the Portuguese in the Swiss labour market, the main obstacles that they have had to face and their prospects for the future.

Francisco Lima da Costa (SociNova - New University of Lisbon) presented the findings of the research that he (and his fellow colleague Catarina Oliveira) carried out on the issue of the "Aspirations and perspectives of Chinese entrepreneurs towards emigration. Preliminary results of the research made in the Qingtian Village, Zhejiang Province (People's Republic of China)". The goal of this research was to understand the role of the social networks that span the sending and receiving countries and, in particular, the role played by the emigrants' families in the migration and settlement processes and in launching businesses. The speaker dwelled on the importance of the family members and fellow countrymen already present in the receiving country in structuring the various immigrant communities. A comparative assessment was made (based on a survey conducted in Qingtian, China) of the universe of formal and informal entrepreneurs in this city, in order to understand the economic integration strategies of the people living there and of those that emigrated to Portugal and Spain.

Maria Lucinda Fonseca and Jorge Macaísta Malheiros (CEG - University of Lisbon) focused on the relationship between immigration and the potential for regional development, drawing on the characteristics of the Portuguese labour market and on the patterns of regional settlement of the recent wave of immigration to Portugal (which consists mostly of Eastern European immigrants and is in many ways different from the previous waves of immigration from the former Portuguese colonies in Africa). The new immigrants have higher levels of education and training and have displayed a tendency to scatter significantly more throughout the country. In their address " New immigration", 
labour market and competitiveness of Portuguese regions", the speakers discussed the new geographic patterns of immigrant settlement, which are in many ways a consequence of local economic dynamics, differential labour markets needs in the various regions and other variables having to do with the regional devel-opment processes. Towards the end of their address, these speakers stressed the potentially positive impact of this "new" immigration to non-metropolitan areas, despite the fact that the professional incorporation strategies of these "over-qualified" immigrants have up until now contributed to "defensive" reactions by their employers - low wages and innovation levels -, thus impinging negatively upon the competitiveness of the Portuguese industries.

The last panel, Frameworking the City: New Populations and Institutions, was chaired by Maria Lucinda Fonseca. The first speaker was Demetrios Papademetriou (Chair Emeritus of the International Metropolis Project and co-Director of the Migration Policy Institute, Washington D.C.), who analysed the current situation of international migration, its recent tendencies and some of its likely future trends.

Rinus Penninx (Director of IMES and Co-Chair of the International Metropolis Project) presented his address entitled "Migration in the city: local citizenship and integration policies", in which he discussed the nature of recent migratory flows in Europe and put forth a typology of national-level responses in European countries - particularly in the field of immigrant hosting and integration. He then proceeded to analyse city-level strategies aimed at dealing with the increasing diversity.

Leticia Calderón-Chelius (Dr. José Maria Luis Mora Research Institute, Mexico) gave out an address entitled "Political rights of citizens living abroad: the perspective of the sending countries", in which she discussed the sending countries' stances with regard to their emigrants. As transnationalism emerges as an increasingly significant phenomenon, some sending countries are only now beginning to react by seeking to foster the establishment of ties between the sending society and its citizens living abroad. In this address, the speaker analysed the case of ten Latin American countries in what regards the promotion of their emigrants' participation in the political process (by allowing them to cast their votes abroad or by creating new types of political representation). These measures are opening the door to a new form of political participation and a new type of citizenship that transcends the borders of the sending country.

The last address in this conference was presented by Jorge Macaísta Malheiros, who analysed the "New spatial order, transnationalism and international links". Analysing the major changes that have affected the world spatial order in the past few decades (as the nation-state configuration is gradually complemented, or even challenged, by a network configuration in which cities play the leading role), Malheiros dwelled on what he considers to be the twin actors that drive this process: large cities, corporations and government institutions, on the one hand; and the transnational immigrant communities that establish links between the large urban centres in the North and the small and medium-sized communities in the developing countries, on the other. This speaker argued that the transnational actions and practises of these groups can be framed within national (particularly, urban) policies aimed at fostering development in both sending and receiving regions.

The proceedings of this International Conference will soon be published under book form and will hopefully convey the interesting and lively debates that took place in these two days. 